\title{
Case report of overcrowded buses and a possible solution
}

\author{
N. M. Gomes Rocha \\ FEUP - Faculdade de Engenharia da Universidade do Porto, \\ PROEC - Projectos, estudos e construções Lda, \\ Braga, Portugal
}

\begin{abstract}
This paper reports a case of overcrowded buses and a possible solution. Project management methodology is used in transport planning.

The paper is divided into three main parts. The first part is raw material. Case report scenario and methodological steps are presented. The second part is the processor. Methodological steps are explored using a specific case as an example. The third part is the final product. The case solution is presented and the lessons learnt are shared.

Project management is used in huge projects, with lots of interlocutors, high quality and environmental standards and higher budgets. In smaller projects, it is considered a waste of resources. This paper tries to prove that with adjustments, project management methodology could be useful in small projects.

Project management classical methodology was used as a base to design a general plan. Parallel to the general plan is the task plan. The task plan organizes the tasks considering project characteristics like working team dimensions, deadlines and budget. In this project a task plan was developed for a one person working team, close deadlines and low budget.

The project management main issue is to always improve the standards so the most important lesson taken from this project was that task organization could define the project success so it should receive close attention.
\end{abstract}

Keywords: urban transport, public transport, transport planning, project management, bus. 


\section{Introduction}

When I faced this situation, my first thought was to gently say to the project owner: Find someone else. However, my first words were: I take it.

Braga is a 2000 year old pre-roman city and the third biggest in Portugal. With a $25 \%$ population growth in the last thirty years, Braga's public transport network has grown in the same way. The city public bus company has 85 different lines, high financial limitations, higher social obligations and a growing demand in two of its most used lines. A simplified and adapted project management methodology (considering PMI-Project Manager Institute devices) was used. So the general plan for this project includes the following steps:

First of all a "Mission" must be defined followed by "Commitment and standard conduct". "Mission limits" definition is the next step. "Global planning" is the fourth step and includes: "Collect/select data", "Strategy", "Data validation", "Data evaluation", "Strategy validation", "Solutions brainstorm", "Impact evaluation", "Solutions validation" and "Project owner presentation". Fifth step of the general plan is "Project life-time management". The last step is "Lessons".

The task plan includes a couple of meetings between the project owner (PO) and the transport planner (TP) to get in contact with the scenario and approve the general plan (Figueroa [1]). The next task for TP is to develop "Global planning". It must be subdivided into actions that include studying the objects, meetings with agents or technical research. PO solution presentation is the next task. After the TP and PO end their communication TP must carefully analyse every step, task and action taken as a final task of the all project (Figueroa [1]).

\section{Project}

\subsection{Mission}

The mission was to study two bus lines and develop capable solutions to its deregulations. Mission definition is a PO function. It should be defined at the first meeting.

\section{Commitment and standard conduct}

Commitment and standard conduct definition is a PO and TP function. Commitment definition depends on PO and TP interrelation. Deadlines, midterm reports, final report and payment definitions have critical importance in the final result.

\subsection{Mission limits}

Three main project limitations were realized after five rounds of discussion:

1. Capitalize on growing demand.

2. Maintain covered areas.

3. Maintain average frequency. 
Capitalization of growing demand is essential to a company's financial balance. Maintaining covered areas, especially in suburbs, is considered crucial to city growing policy. Reducing average frequency will definitely receive social opposition (Cassir and Bell [2]).

Mission limits final definition is a PO function; however TP, in an interactive process and considering territorial reality, should supply justified analyses. TP could develop a questioner on PO desires, needs and constraints (Figueroa [1]). This will help PO in clarifying positions.

\subsection{Global planning}

Global planning should be defined in assembly; however TP could define and submit it for PO validation and counselling.

\subsubsection{Collect/select data}

Network relevant data: $65 \%$ of network serves $35 \%$ of population. $60 \%$ of passengers are considered frequent.

Lines relevant data: $15 \%$ of total network passengers use these lines.

TP should collect/select information considering mission definition and network knowledge. Information unavailability is a common problem, so TP must draft the required information. In a first contact, TP should collect/select city data (history, demography or unemployment), network data (company income/spending distribution or typical passenger and fleet characteristics) and lines data (number of passenger per line or pre-developed solutions) (Robusté [3]).

\subsubsection{Strategy}

Both lines are radial, crossing city centre from west to east suburbs. However covered areas, in suburbs, are substantially different. Overcrowding and growing demand problems, according to PO information, start a couple of stops before city centre limits.

Optimize offer/demand relation is the initial strategy (Steenbrink [4]). A sustainable mobility paradigm is based on two principles: derived demand and travel costs minimization (Banister [5]). In this case, population demographic distribution crossed with network density map indicates potential increased costs. Passenger numbers transported per resident population, in suburbs, are three times higher than in the city centre.

Data analysis and network knowledge have crucial importance in a sustainable strategy (Vuchic [6]); however, especially in more complex cases, it is better to have an initial doubtable strategy than have nothing. Future stages will help TP to clarify positions.

\subsubsection{Data validation}

Mobility report inexistence made land research essential. The required information draft was developed into a final paper and population mobility characteristics, passengers' streams per line, travel time between stops, and passenger concerns were the studied points (Hutchinson [7]). 


\subsubsection{Mobility}

Budget and deadline limitations incapacitate a complete mobility report. So in loco experience was developed to surpass this problem (Hutchinson [7]). The city was divided into: city centre, first ring and second ring (suburbs). For each segment, a point ' $\mathrm{X}$ ' was defined, considering demographic distribution. Using typical mobility factors (public services, jobs and shops), the city centre was considered to be the main mobility generator (Robusté [3]). So for each segment public transport travel time (PTTT), private vehicle travel time (PVTT) and parking time (PT) were determined. Considering only time factor, and minimizing public transport deficit to private vehicles, waiting time (WT) was determined using the following equation:

$$
\mathrm{WT}=\mathrm{PVTT}+\mathrm{PT}-\mathrm{PTTT}
$$

In the limit, WT is public transport frequency. On average, for the city centre, a bus should pass every $9 \mathrm{~min}$, in the first ring, every $20 \mathrm{~min}$ and in the second ring, every $35 \mathrm{~min}$.

\subsubsection{Streams}

Considering the city centre, first ring and second ring division and adding west and east, the city can be divided into city centre west $(\mathrm{CCW})$, city centre east (CCE), first ring west (FRW), first ring east (FRE), second ring west (SRW) and second ring east (SRE) segments (Rodrigue et al. [8]).

Main streams, with specific variations according to each line, have on average:

1. high intensity between FRW-city centre-FRE ( $71 \%$ of all validations),

2. medium intensity between SRW-CCW ( $20 \%$ of all validations),

3. low intensity between SRE-CCE ( $9 \%$ of all validations).

Other streams are statistically insignificant representing less than $1 \%$ of all validations.

\subsubsection{Travel times}

For line A, in rush hour, the total travel time (TTT) is 90 min and frequency is $35 \mathrm{~min}$. In the remaining hours, TTT is $65 \mathrm{~min}$ and frequency is $22 \mathrm{~min}$. The average frequency is $29 \mathrm{~min}$ with three buses used. For line B, in rush hour, TTT is $110 \mathrm{~min}$ and frequency is $34 \mathrm{~min}$. In the remaining hours, TTT is $90 \mathrm{~min}$ and frequency is $23 \mathrm{~min}$. The average frequency is $30 \mathrm{~min}$ with four buses used.

\subsubsection{Passenger concerns}

Main passenger concerns were about low frequencies, high journey sinuousness and information accessibility.

\subsubsection{Evaluate data}

Determine factors that, positively or negatively, influence the performance of both lines (White [9]). Studied elements were efficiency/costs and externalities. 


\subsubsection{Efficiency/costs}

Both lines efficiency maximization and costs minimization are negatively affected by the SRE-FRE segment. Passengers per journey, in this segment, are three times lower than the line average. This means that transportation costs are increased compared to line average.

\subsubsection{Externalities}

During normal hours, public transport travel time (PTTT) between FRW-CCW is equal to walking travel time (WTT) for the same segment. In rush hours PTTT = 1.3WTT. For this segment, in terms of time, public transport is not advantageous (Patricksson and Labbé [10]).

\subsubsection{Strategy validation}

Differences between desirable frequencies calculated with in loco experience and frequencies obtained during travel times counting, streams distribution and efficiency/costs differences between segments, confirms offer/demands deregulations (Huapu and Ye [11]). These deregulations represent increased costs to potential/effective demand validating previous strategy (Steenbrick [4]).

\subsubsection{Solutions brainstorm}

Solution 1: create one interface and maintain journeys. Solution 2: create two interfaces and maintain journeys. Solution 3: create two interfaces and melt journeys.

Table 1: $\quad$ Brainstormed solutions.

\begin{tabular}{|c|c|c|c|c|c|c|}
\hline & \multicolumn{2}{|c|}{ Solution 1 } & \multicolumn{2}{c|}{ Solution 2 } & \multicolumn{2}{c|}{ Solution 3 } \\
\hline Segment & Description & Buses & Description & Buses & Description & Buses \\
\hline 1 & $\begin{array}{c}\text { SRW-FRW } \\
\text { (line A) }\end{array}$ & 1 & $\begin{array}{c}\text { SRW-FRW } \\
\text { (line A) }\end{array}$ & 1 & $\begin{array}{c}\text { SRW (line A)-FRW- } \\
\text { SRW (line B) }\end{array}$ & 3 \\
\hline 2 & $\begin{array}{c}\text { SRW-FRW } \\
\text { (line B) }\end{array}$ & 1 & $\begin{array}{c}\text { SRW-FRW } \\
\text { (line B) }\end{array}$ & 1 & FRW-FRE & 3 \\
\hline 3 & $\begin{array}{c}\text { FRW-SRE } \\
\text { (line A) }\end{array}$ & 2 & FRW-FRE & 3 & $\begin{array}{c}\text { SRE (line A)-FRE- } \\
\text { SRE (line B) }\end{array}$ & 1 \\
\hline 5 & $\begin{array}{c}\text { FRW-SRE } \\
\text { (line B) }\end{array}$ & 3 & $\begin{array}{c}\text { FRE-SRE } \\
\text { line A) }\end{array}$ & 1 & & \\
\hline & & $\begin{array}{c}\text { FRE-SRE } \\
\text { (line B) }\end{array}$ & 1 & & \\
\hline
\end{tabular}

\subsubsection{Impacts evaluation}

\subsubsection{Frequencies}

Frequencies were calculated considering travel times between points for existing conditions (Patricksson and Labbé [10]). 
Table 2: $\quad$ Average frequency ( $\mathrm{min})$ per segment.

\begin{tabular}{|c|c|c|c|c|c|c|c|c|c|c|c|c|}
\hline & \multicolumn{4}{|c|}{ Solution 1 } & \multicolumn{4}{c|}{ Solution 2 } & \multicolumn{3}{c|}{ Solution 3 } \\
\hline Segment & 1 & 2 & 3 & 4 & 1 & 2 & 3 & 4 & 5 & 1 & 2 & 3 \\
\hline $\begin{array}{c}\text { Average } \\
\text { frequency (min) }\end{array}$ & 30 & 35 & 27 & 30 & 30 & 35 & 15 & 12 & 16 & 28 & 15 & 30 \\
\hline
\end{tabular}

For solution 1 the frequency remains almost the same in every segment. For solution 2 the frequency is raised in segments 3,4 and 5. For solution 3 the frequency is raised in segment 2. A simulation test proves that for segments 3,4 and 5 of solution 2 and segment 2 of solution 3, with those frequencies, the time spent in stops is reduced by a minimum of $10 \%$, so the maximum frequency would be:

Table 3: $\quad$ Maximum frequency ( $\mathrm{min}$ ) for solutions 2 and 3.

\begin{tabular}{|c|c|c|c|c|c|c|c|c|}
\hline & \multicolumn{4}{|c|}{ Solution 2 } & \multicolumn{3}{c|}{ Solution 3 } \\
\hline Segment & 1 & 2 & 3 & 4 & 5 & 1 & 2 & 3 \\
\hline Average frequency (min) & 30 & 35 & 14 & 10 & 13 & 28 & 14 & 30 \\
\hline
\end{tabular}

\subsubsection{Covered areas}

Interfaces creation could negatively affect demand; however the FRW interface is minimized by WTT $\leq$ PTTT. The FRE interface, for solutions 2 and 3, is minimized by low demands in served segments (De Witt et al [12]).

\subsubsection{Demand capitalization}

If the frequency is increased, the offer of transport increases so the probability that the demand uses the transport service increases (Chen et al [13]).

For solution 1 growing demand is happening in part of segments 3 and 4 . The average frequency in those segments remains almost unchanged so a frequency increasing is only possible with extreme coordination of timetables in those segments. Company's previous attempts of high coordination levels were abandoned. Demand capitalization level for this solution was not quantified although it is not too much different from existing levels.

To quantify the level of demand capitalization (DC) for solutions 2 and 3 it was determined:

$$
\begin{gathered}
\mathrm{DC}=(\mathrm{OT} / \mathrm{DT}) \times 100 \% \\
\mathrm{OT}=(\mathrm{B} \times \mathrm{C}) \times \mathrm{T} \\
\mathrm{DT}=\mathrm{V}+\mathrm{DV}
\end{gathered}
$$

OT - Offer of transport

DT - Demand of transport

B - Number of buses

$\mathrm{C}$ - Average buses capacity

$\mathrm{T}$ - Number of buses travels/day

$\mathrm{V}$ - Number of validations

DV - Historical demand variation. 
Table 4: $\quad$ Demand capitalization levels for solutions 2 and 3.

\begin{tabular}{|c|c|c|c|c|c|c|c|c|}
\hline & \multicolumn{4}{|c|}{ Solution 2 } & \multicolumn{3}{|c|}{ Solution 3 } \\
\hline Segment & 1 & 2 & 3 & 4 & 5 & 1 & 2 & 3 \\
\hline DC (\%) & 112 & 92 & 108 & 217 & 205 & 101 & 108 & 160 \\
\hline
\end{tabular}

\subsubsection{Solutions validation}

Considering "Impact evaluation" every solution is implementable although solution 1 seems to be the most difficult. Solution 3 has the best offer/demand distribution. Despite it releasing short time problems, definitely in the future more resources will be needed and a rail solution could become viable (Cassir and Bell [2]).

\section{Final product}

\subsection{Solution presentation}

Graphic aspects should receive equal importance of contents. The final report must have clear writing and logical justification to every conclusion and connection (Figueroa [1]). If PO requires a formal meeting, TP should prepare a presentation with the most important aspects and foresee possible doubts.

\subsection{Project life-time management}

\subsubsection{Deadlines}

Deadline definition is a PO function. Deadline management has four stages: objectives, plan, program and control.

During "Objectives" deadlines, generic and specific objectives must be defined. During "Plan" every project activity must be divided in sub activities and dependences, duration and staff resources between activities must be defined.

During "Program" sub activities are divided in actions and assigned to project staff.

"Control" is essential and could be done by comparative analysis or using simulation resources (Figueroa [1]).

\subsubsection{Budget}

Historically, budget fulfilment is the PO's top desire. So any cost increase must be validated by PO. The budget plan must be associated with the deadline plan. The final report should have associated a compared analysis between an initial budget and effective budget and justification for positive and negative detours.

\subsection{Lesson}

The whole project was a lesson. Especially because constraints were huge compared to the potential impact. The main difference between university and economy exercises is that in university you only need to be good enough to pass, but in economy you must be a perfectionist. Task organization learning will be important in future projects. 


\section{References}

[1] Figueroa, M. S., Gestión integrada de proyectos, UPC, 2001.

[2] Cassir, C., Bell, M. G. H., Transportation Planning State of the Art, Kluwer Academic Publishers, 2002.

[3] Robusté, F., Apunts Planificació del Transport, UPC, 1994.

[4] Steenbrink, P. A., Optimization of Transport Networks, A WileyInterscience Publication, 1974.

[5] Banister, D., The Sustainable Mobility Paradigm, Transport Policy 15, pp. 73-80, 2008.

[6] Vuchic, V., Urban Public Transportation, Prentice Hall, 1981.

[7] Hutchinson, B. G., Principles of Urban Transport Systems Planning, Scripta Book Company, 1974.

[8] Rodrigue, J.-P., Comtois, C., Slack, B., The Geography of Transport Systems, Routledge, 2006.

[9] White, P. R., Planning for Public Transport, Hutchinson \& Co (Publishers) Ltd, 1976.

[10] Patricksson, M., Labbé, M. (Eds), Estimation of Travel Time Reliability, Kluwer Academic Publishers, 2002.

[11] Huapu, L., Ye, S., Complexity of Public Transport Networks, Tsinghua Science and Technology 12 (2), pp. 204-213, 2007.

[12] De Witt, A. et al., The Impact of "Free" Public Transport: The Case of Brussels, Transportation Research Part A 40, pp. 671-689, 2006.

[13] Chen, Y.-Z., Li, N., He, D.-R., A Study on some Urban Bus Transport Networks, Physica A 376, pp. 747-754, 2007. 